\title{
Distributed Manufacturing: A New Digital Framework for Sustainable Modular Construction
}

\author{
Chris Turner ${ }^{1, * \mathbb{D}}$, John Oyekan ${ }^{2}$ and Lampros K. Stergioulas ${ }^{3}$ (D) \\ 1 Surrey Business School, University of Surrey, Guildford GU2 7XH, UK \\ 2 Department of Automatic Control \& Systems Engineering, University of Sheffield, Sheffield S10 2TN, UK; \\ j.oyekan@sheffield.ac.uk \\ 3 Data Science Research Group, Faculty of IT \& Design, The Hague University of Applied Sciences, \\ 2501 EH Den Haag, The Netherlands; 1.stergioulas@hhs.nl \\ * Correspondence: christopher.turner@surrey.ac.uk
}

Citation: Turner, C.; Oyekan, J.;

Stergioulas, L.K. Distributed

Manufacturing: A New Digital

Framework for Sustainable Modular

Construction. Sustainability 2021, 13,

1515. https://doi.org/10.3390/

su13031515

Academic Editor: Castorina

Silva Vieira

Received: 9 December 2020

Accepted: 27 January 2021

Published: 1 February 2021

Publisher's Note: MDPI stays neutral with regard to jurisdictional claims in published maps and institutional affiliations.

Copyright: (c) 2021 by the authors. Licensee MDPI, Basel, Switzerland. This article is an open access article distributed under the terms and conditions of the Creative Commons Attribution (CC BY) license (https:// creativecommons.org/licenses/by/ $4.0 /$ )

\begin{abstract}
This paper explores the notion of the modular building construction site as an applied instance of redistributed manufacturing; in so doing, this research seeks to reduce the environmental footprint of building sites, treating them as small digitally connected subunits. In seeking to provide a whole lifecycle appreciation of a construction project, it is noted that the presence of a framework to provide guidance on the consideration of Internet of Things (IoT) data streams and connected construction objects is currently lacking. This paper proposes use of embedded IoT enabled sensing technology within all stages of a modular building lifecycle. An expanded four-phase model of intelligent assets use in construction is proposed along with an outline of the required data flows between the stages of a given building's entire lifecycle that need to be facilitated for a BIM (Buildings Information Modelling) representation to begin to describe a building project as a sustainable asset within the circular economy. This paper also describes the use of concrete as a modular sensing structure; proposing that health monitoring of the material in situ along with the recoding of environmental factors over time could help to extend the longevity of such structures.
\end{abstract}

Keywords: redistributed manufacturing; sustainable construction; sensor networks; industry 4.0

\section{Introduction}

In recent years, there has been a shift towards more sustainable methods of construction. One of the earliest paradigms to include enhanced awareness of environmental impact is that of lean construction. Lean construction [1] theory is derived from lean manufacturing where constituent activities are modified to optimize waste elimination and engender a continuous process improvement cycle (among other aims). In terms of construction, lean principles are also focused on the reduction of waste and increasingly on the goal of sustainable building practices [1,2]. Modular building methods [3] are also being developed with sustainable construction goals in mind. Modular construction can be thought of as an industrialized building system where parts of a building will be formed offsite (potentially within a factory) in the form of modules [3]. Once onsite, building modules may be quickly assembled into the completed construction.

A relatively new methodology has arisen in manufacturing research that seeks to reduce the environmental footprint of often monolithic manufacturing facilities by dividing their productive capabilities between a number of small digitally connected sub-production units (often located closer to local markets where their products will be sold). Redistributed Manufacturing (RDM) [4] describes this movement, which is allied with that of Distributed Manufacturing (DM), defined as "the ability to personalize product manufacturing at multiple scales and locations ..." [4].

In this paper, we suggest that sustainable modular construction can be considered in terms of the Distributed Manufacturing paradigm and thus propose a framework that 
utilizes advances in sensing technologies to provide a new level of control of environmental parameters in meeting increasingly challenging sustainability goals faced by housing developers in the near future.

This paper is organized into the following sections. Section 2 presents the relevant research and examines the current research directions in sustainable construction practice and drivers relevant for the realization of a framework for distributed sustainable construction. Section 3 describes the methodological approach, outlining the main components of the framework for sustainable modular construction. Section 4 presents the proposed framework and details the central considerations and mode of operation of the approach proposed by this paper. Section 5 examines concrete as a modular sensing structure and expands on the agenda for the embedding of sensing technology within construction materials. Section 6 (Conclusion) summarizes the framework, its potential role in the achievement of sustainable construction of modular buildings, and future research directions.

\section{Relevant Research}

Lean construction is seen by the authors of [1] as one of the foundation viewpoints for the consideration of environmental factors within construction. Lean construction [1] theory is derived from lean manufacturing, where constituent activities are modified to optimize waste elimination and engender a continuous process improvement cycle (among other aims). As with its use in manufacturing, the minimization of waste is of prime consideration in lean construction [1]. Gaining in acceptance, the practice of modular building is best described as "a hybrid of construction and manufacturing" [2], involving the manufacture of modules within a factory environment and the transportation of the modules to site for rapid assembly into a completed structure. Modularity has long been seen as a beneficial strategy within product design and manufacture [5]; the extension of this philosophy into construction is seen by some as a natural progression. The combination of lean methodology with modular construction techniques has been explored by Innella et al. [2] who focus on the capability of this approach to minimize waste both at the manufacturing and on-site assembly (construction) stages of a build. Modular construction is also the subject of research by Ferdous et al. [6], who acknowledge that the construction industry still has to adapt from a reliance on traditional building methods and fully understand the benefits of modular construction. While modular construction is more commonly used in commercial and industrial property projects, these authors also point to the need to popularize this mode of construction with house-builders [6,7], citing the need for logistical support and training as currently being lacking.

The realization of modular construction as a more environmentally acceptable mode of building is advocated in [8], though it is emphasized that a major area still to be addressed is the need for improved coordination and communication between building site and the manufacturing facility responsible for the modular units. Hyun et al. [9] put forward an integrated design process for modular construction projects using an approach that utilizes Dependency Structure Matrix; the authors of this work highlight the need for early stage development of commination channels between all participants in the design process and shared processes. Xu et al. [10] conducted a review of modular construction methods, finding that as yet no holistic set of standards exist for the comprehensive adoption of modular construction methods. Modular construction has its roots in the prefabricated buildings movement of the 1950s [11], though the introduction of modern manufacturing methods along with the ability to digitally incorporate individual customers' needs at the design stage has helped to promote this building mode in more recent years [12]. The types of prefabricated building elements and modules are now developed with carbon emissions and environmental goals in mind [11,13]. In the assessment of the carbon footprint of a prefabricated building the Life Cycle Assessment (LCA) approach is of particular interest $[13,14]$. LCA allows the measurement of a range of economic and environmental factors relating to a particular construction over its entire lifespan [15]. Kamali and Hewage [15] put forward an extension of the LCA approach relating to the 
further exploration of sustainability measures in relation to modular building construction. In this work [15], we highlight social factors, such as health of occupants, and the need for their inclusion in a sustainability score for modular housing design and construction. The reduction in waste material produced in the construction process is the focus of Lehmann [16], citing prefabrication as a way to control use of excess materials in the onsite construction phase of a build. In terms of building waste, $\mathrm{Wu}$ et al. [17] make the case for an assessment of research in the reuse of construction waste from a materials science perspective to underpin the environmental and logistics benefits espoused by modular housing studies; similarly, Leder et al. [18] urge an evaluation of the economic assessment of such waste and its further treatment and/or reuse. Offsite construction, required by modular building designs, is still seen by some as an answer to the increasing worldwide need for the rapid provision of affordable new homes $[19,20]$.

In seeking to digitize modular construction projects, for the purposes of improved control and management, Building Information Modeling (BIM) models are now increasingly popular. BIM is a digital facsimile of a building detailing its physical dimensions and functional specification [21]. BIM is also seen as an enabler in the goal of achieving zero carbon rated status for new builds [22]. Zaid et al. [22] utilize BIM with the Framework of Sustainable Strategic Development (FSSD) [23] to enable design-connected assessments of environmental impacts of projects before construction commences. Gbadamosi et al. [24] also investigate the use of BIM with lean construction for optimal on site assembly of building modules onsite.

The achievement of sustainable construction practice has been an active research area for more than 10 years, and recently the contextualization of this field within the Circular Economy agenda has provided additional motivation. Initially the Circular Economy (CE) concept was utilized for a consideration of waste streams produced by construction sites and the potential for the recycling of excess building materials $[25,26]$. CE is also being used to focus efforts to introduce design strategies that maximize end of life reuse of building materials and minimize energy use of buildings while in occupation [27]. The Circular Economy concept is defined as a movement away from the linear mindset of the current economy model that espouses a "take, make, and dispose" attitude to natural resources [28]. The Circular Economy reflects a new attitude towards resources as being finite and capable of being maintained at a high state of utility [28]. Osobajo et al. [29] note the increasing interest in the CE agenda but also acknowledge the challenges still faced in further popularizing the aims within the construction sector. It is also the case that further investigations into $\mathrm{CE}$ aiming at adoption within the construction industry should be validated with quantitative studies [29]. It is the opinion of the authors of [30] that the entire supply chain for construction should be involved in the achievement of Circular Economy aims not just the immediate building contractors. Many authors favor the revised utilization of local resources in building projects, allowing the shortening of supply chains [31] and the possibility for closed loop (circular) supply relationships where materials are reused and remanufactured into new building components [32]. The term "cradle to cradle" has been used to describe the potential to reuse materials (extending their lifespan), and this concept has been explored by works such as that in [33], whose authors examine the recycling of steel wall framing components through disassembly. These authors, while acknowledging the potential of reuse, note that there is reluctance in the construction industry at large to adopt this philosophy [33]. To this end, Tingley et al. [34] advise that the creation of a database of suppliers and reused sections would be beneficial along with supporting technical guidance as to the correct reuse process for building materials.

Ruiz et al. [35] put forward a framework for the implantation of Circular Economy in construction with a particular focus on demolition waste. These authors make the case for selective deconstruction of buildings due to be demolished and recovery of materials as an integrated part of a building's lifecycle [35]. Ghisellini et al. [36,37] also make the case for deconstruction and selective demolition along with an agenda for the recognition for waste minimization, end of life disassembly, and materials reuse potential at the design 
stage. An LCA-based approach to design for deconstruction has been proposed in [38]; inherent in this approach is the methodology for design for deconstruction, which has been implemented within a software tool. Akinade et al. [39] provide a survey to establish the critical success factors behind effective material recovery strategy within a design for deconstruction methodology; finding that non-technical factors in particular, such as competence in disassembly and legislation, are significant factors. A set of analytics for disassembly and deconstruction is proposed by Akanbi et al. [40] to maintain materials use within the economy and via a containing application provide a platform for both planners and building designers. Nußholz et al. [41] examine potential business models to facilitate the economic reuse of building materials and changes in policy required to support secondary material utilization. Pan et al. [42] extend the concept of recycling construction waste through the use of reverse logistics networks. The authors of [42] also acknowledge that the employment of such a reverse logistics system on a wider basis would require investment in local recycling plants and a more in depth investigation utilizing agent based simulation may be required to fully understand the implications of such a system on a country basis. The work of Buyle et al. [43] introduces the concept of demountable wall sections and their use in realizing Circular Economy goals within construction. The authors [43] also point to the current lack of quantitative studies assessing the environmental impact of such innovations in the construction industry.

It is the case that the Circular Economy paradigm provides much context and impetus for the realization of sustainability within the construction industry. Increasingly, modern construction projects are seen as assembly operations consisting of the composition of pre-build modular parts on a building site with integrated treatments and mitigation of inherent wastes [44-48]. The Distributed Manufacturing model [4] has much to offer the sustainable modular construction process as it provides a potential organizational template; describing customized manufacture, shortened supply chains, and local on-site assembly. Utilizing digital network technologies and modern manufacturing methods derived from the Industry 4.0 paradigm, Distributed Manufacturing aims to provide customized products to local markets in a sustainable fashion [49]. Such smaller scale distributed production mirrors some of the current modular housing production process, with the main differences being the lack of digital connectivity between design, production, and on-site assembly, and the case that much manufacturing of the modular sections is undertaken in centralized production facilities. With the popularization of modular building, however, the opportunity of local production and near to real-time digital connectivity throughout the design, construction, use, and eventual disassembly of a housing unit could bring real change to the industry and help it to achieve present and future environmental standards.

\section{Methodological Approach}

This paper puts forward a framework for sustainable modular construction utilizing a distributed manufacturing approach. The framework is a result of a state-of-the-art in-depth review of modular and sustainable construction literature along with an extension to the three-phase use of intelligent assets in construction from the work in [50] to recognize the end of life use of materials and disassembly of the building. The new four-phase model is an integral part of the framework and provides a digital thread connecting design all the way through to building asset end of life and reuse.

The main steps of the methodological approach employed are shown in Figure 1 above. Continuing from the literature review stage, consideration will be given to the existing three-stage model of intelligent asset use in construction [50] and discussion offered on the use of sensor technology to provide assets end of life and recycling guidance to workers involved in buildings demolition/disassembly (detailed in Section 4). The adaptation stage demonstrates how the intelligent assets for the construction model will be adapted to enable sustainable construction, and the model will be integrated into a distributed manufacturing approach (Section 5). The completed framework is discussed and displayed in Section 6, followed by conclusions and future research directions. 


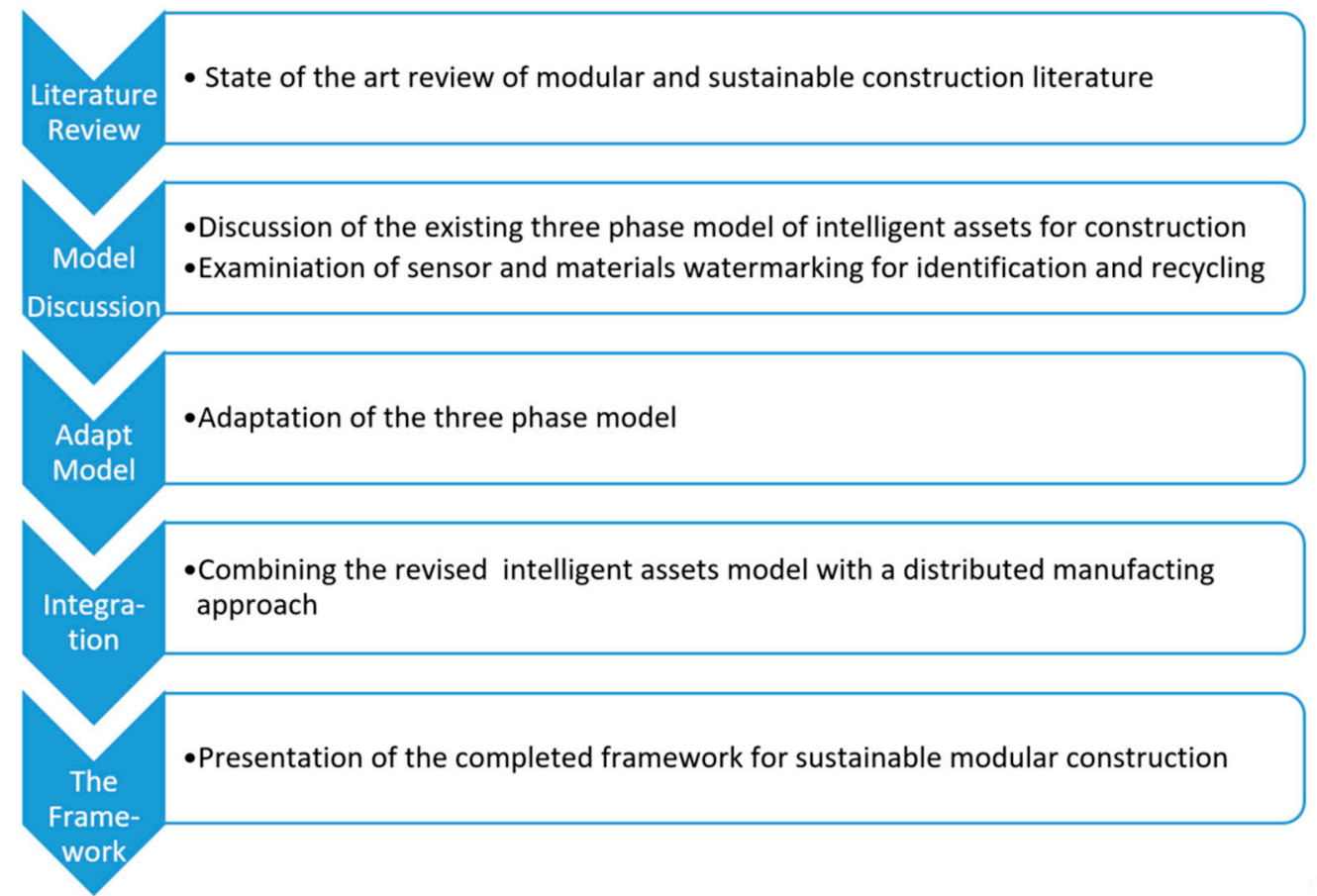

Figure 1. Main stages of the methodological approach employed.

\section{Intelligent Asset Use in Construction}

It is clear from the literature that a scope exists for a clear and better defined "digital thread" to connect together the building design and manufacturing stages with the onsite assembly stage and the eventual end of life disassembly stage (possible with the modular building format). The collection of data at three stages of manufacturing, on-site assembly/construction, and occupation (building in use) can be seen below in Figure 2.

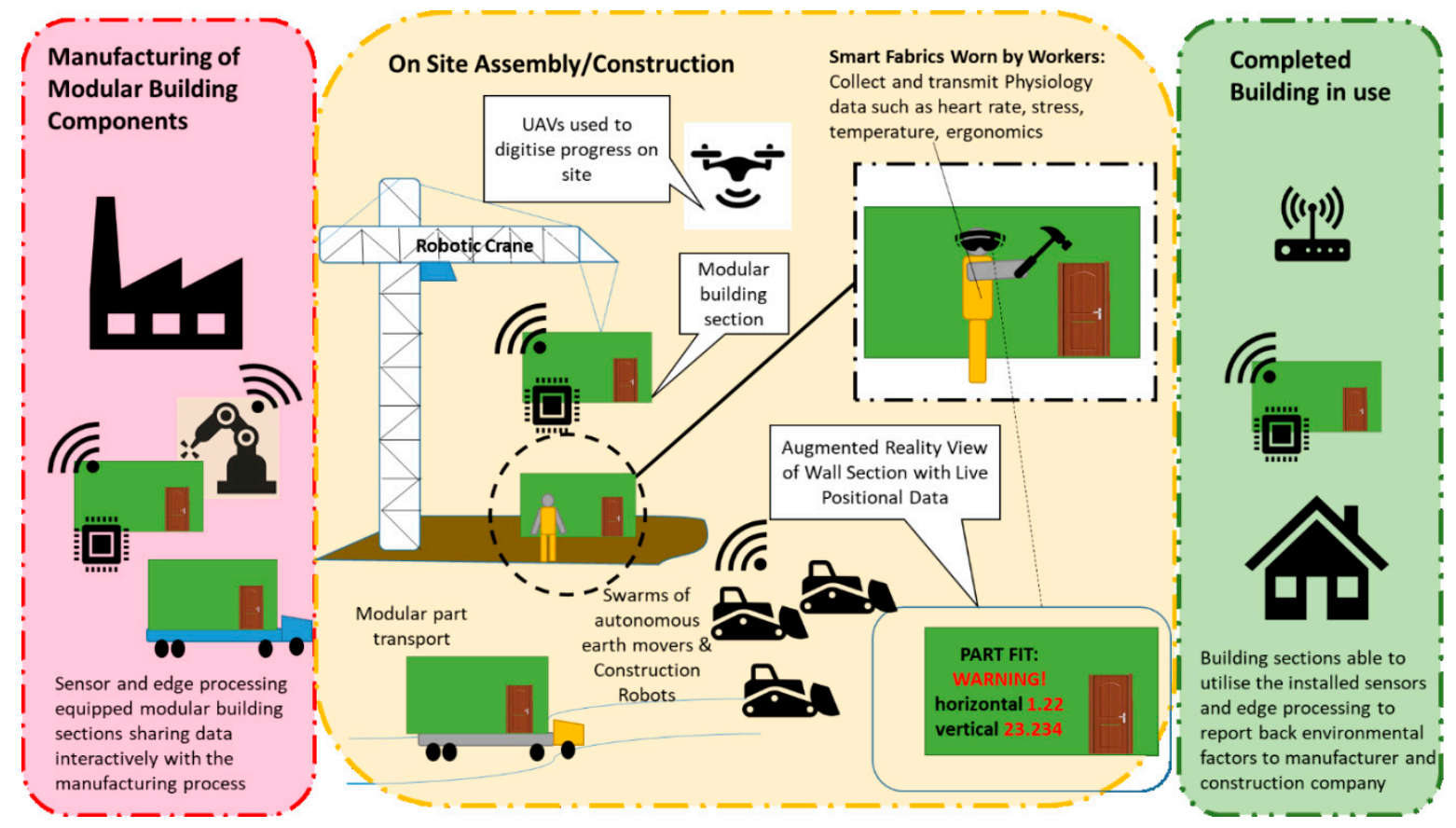

Figure 2. A three-phase model of intelligent assets use in construction (taken from the work in [50]).

The model in Figure 2 demonstrates the possibilities to utilize a sensor pack consisting of onboard Edge computation and wireless connectivity with an onboard power 
supply [50] to provide sensing and data sharing between a modular building component and the production line manufacturing it; communication between the modular building component and onsite machinery and workers involved in assembling it into a completed building; and environment sensing within a building when in use to help in the adjustment of, for example, heating and ventilation levels and the performance of the module (with such data possibly being sent back to the manufacturer for assessment and learning in the development of new products). The sensor pack would be able to provide this three-phase use sensing and intelligent data processing in situ within the modular building component [50]. Table 1 further illustrates the intelligent assets in construction three-phase use. Table 2 details different communication protocols and their features that may be used by the sensor pack in the three phases and in general on the Industry 4.0-enabled construction site.

Table 1. Intelligent assets in construction: three-phase use (taken from the work in [50]).

\begin{tabular}{|c|c|c|}
\hline Intelligent Asset & Manufacture & On-Site Assembly \\
\hline Scenario/Application & $\begin{array}{l}\text { An intelligent modular wall } \\
\text { section being manufactured is } \\
\text { able to share data with the } \\
\text { manufacturing process to } \\
\text { ensure in time delivery of } \\
\text { sub-components and assist } \\
\text { with their insertion. }\end{array}$ & $\begin{array}{l}\text { A modular wall section being } \\
\text { incorporated into a building is } \\
\text { able to assist a builder by } \\
\text { providing information } \\
\text { regarding its fine positioning } \\
\text { and attachment in relation to } \\
\text { other already assembled } \\
\text { building sections. }\end{array}$ \\
\hline
\end{tabular}

- A modular wall section is able to relay data back to a house owner's intelligent hub.

- Data relayed include house temperature and humidity of wall section (perhaps to alert about water/damp ingress).

- $\quad$ Provided consent is given, it might also be able to send data back to manufacturers.

\begin{tabular}{|c|c|}
\hline $\begin{array}{l}\text { Potential Sensors to apply at } \\
\text { each phase. }\end{array}$ & $\begin{array}{l}\text { Typical embedded sensors } \\
\text { could include orientation, } \\
\text { vibration, and temperature } \\
\text { sensors. }\end{array}$ \\
\hline $\begin{array}{c}\text { Communication types and } \\
\text { properties required at } \\
\text { each phase. }\end{array}$ & $\begin{array}{l}\text { Short-range communication } \\
\text { protocols such as Bluetooth or } \\
\text { ZigBee will ensure that } \\
\text { communication stays local but } \\
\text { also allow a mesh type } \\
\text { network to be constructed for } \\
\text { easy transferring and sharing } \\
\text { of data. }\end{array}$ \\
\hline
\end{tabular}

Typical embedded sensors vibration, and temperature sensors.
Typical embedded sensors could include orientation, RFID, and IR sensors to ensure correct positioning and alignment between panels.
Typical embedded sensors could include temperature, humidity, lighting, and chemical sensors to measure pollutants and carbon monoxide levels.

- Typical communication

Depending on the size of the construction site medium to large range communication protocols such as Zigbee, $\mathrm{WiFi}$, or LoRaWAN could be useful in ensuring site wide communications between assets and workers. protocols could be short range such as $\mathrm{WiFi}$, Zigbee, or Bluetooth.

- If consent is given, internet technology could be used to transmit the data out of a user's home to the manufacturer's factories.

- Process conditions such as temperature and vibration could aid in identifying optimal process parameters and predicting breakdowns;

Potential data use in digital twins at each phase
- Positioning data sent in real-time to workers to communicate exact proximity to work pieces.

- $\quad$ Alerting workers to potential dangerous unseen situations

- Data from sensors will be used for inventory update and simulation
- Live feed of time and motion data to construction schedule
- Data could be used to inform the next generation of products for the next buildings allowing for automatic updates to designs.

- Data could be played back to assess how the structure changes with environmental conditions and usage. 
Table 2. Showing different communication protocols and their features (taken from the work in [50]).

\begin{tabular}{|c|c|c|c|c|}
\hline $\begin{array}{c}\text { Communication } \\
\text { Type }\end{array}$ & Standard & Frequency & Range & Data Rates \\
\hline Bluetooth & Bluetooth 4.2 & $2.4 \mathrm{GHz}$ & $50-150 \mathrm{~nm}$ & $1 \mathrm{Mbps}$ \\
\hline ZigBee 3.0 & $\begin{array}{c}\text { Based on } \\
\text { IEEE802.15.4 }\end{array}$ & $2.4 \mathrm{GHz}$ & $10-150 \mathrm{~m}$ & $250 \mathrm{Kbps}$ \\
\hline WiFi & $\begin{array}{l}\text { Based on } \\
\text { IEEE802.11 }\end{array}$ & $\begin{array}{l}2.4 \mathrm{Ghz} \text { and } \\
5 \mathrm{GHz} \text { bands }\end{array}$ & $\begin{array}{l}\text { Approximately } \\
50 \mathrm{~m}\end{array}$ & $\begin{array}{c}\text { 150-200 Mbps, } \\
600 \mathrm{Mbps} \\
\text { maximum }\end{array}$ \\
\hline LoRaWAN & LoRaWAN & Various & $\begin{array}{c}2-5 \mathrm{~km} \text { (urban } \\
\text { area), } 15 \mathrm{~km} \\
\text { (suburban area) }\end{array}$ & $0.3-50 \mathrm{kbps}$ \\
\hline Cellular & $\begin{array}{c}\text { GSM/GPRS/EDGE } \\
\text { (2G), } \\
\text { UMTS/HSPA } \\
(3 G), \text { LTE }(4 G)\end{array}$ & $\begin{array}{c}900 / 1800 / 1900 \\
/ 2100 \mathrm{MHz}\end{array}$ & $\begin{array}{c}85 \text { km(GSM); } \\
200 \text { km (HSPA) }\end{array}$ & $\begin{array}{c}\text { 35-170 kps } \\
\text { (GPRS), 120-384 } \\
\text { kbps (EDGE), } \\
384 \text { Kbps-2 } \\
\text { Mbps (UMTS), } \\
600 \text { kbps-10 } \\
\text { Mbps (HSPA) } \\
\text { 3-10 Mbps (LTE) }\end{array}$ \\
\hline
\end{tabular}

It is the case that this three-phase model could be extended further to enable the use of the sensor pack and/or embedded sensors within modular components to play a part in a building's eventual disassembly and recycling.

\section{Digital Watermark for Materials}

It is the case that for end of life recycling of building components and materials and disassembly operations to become routine in the future, detailed information needs to be made available regarding the composition and handling of such entities. To this end, Honic et al. [51] make the case for a building material passport. This approach effectively proposes an inventory of the materials a building is to be composed of with digital links to a Buildings Information Model (BIM) and the possibility to provide the parameters in the form of an externally available database. Jensen and Sommer [52] also highlight the possible role for a materials passport stating that the disassembly and recycling process would benefit from such a system. Heisel et al. [53] highlight the need for circularity indicators to show how a particular material rates in terms of circularity given its construction, use, and potential for reuse; in this work [53], we view buildings as material stores.

It is the case that most works in the area of materials identification and circularity rating focus on static methods to collect data relating to individual buildings. Though it is the case that sensors and embedded Radio Frequency (RFID) tags may also have a role to play in the dynamic identification of materials, their actual in field environmental performance and the ability to provide information or even give active assistance to the end of life disassembly and recycling processes. The Ellen McArthur Foundation [54] makes the case for the use of intelligent assets in achieving circular economy objectives. In [54], the case is made for the use of sensor systems to provide information on how a building is performing when occupied and in use, along with the compilation of data on materials use and potential for recycling. To take this notion a stage further, the combination of dynamic sensor streams in all stages of building material and modular section use would provide a more holistic picture within a sustainable construction industry and economy. To provide such a picture, it would also be beneficial to process the data from such sensors and tags using artificial intelligence techniques as proposed in [55]. 


\section{Adaptation of the Three-Phase Model for Intelligent Asset Use in Construction in the Context of Distributed Manufacturing}

In Figure 3, a four-phase model of the use of Intelligent Assets in Construction can be seen. Adapted from the three-phase model (Figure 2), the main innovations are the inclusion of the final stage of end of life disassembly and recycling of modular components and their constituent materials. The modular sections will have sensor packs capable of assisting in the disassembly process (similar to fine maneuvering of the section as with onsite assembly usage) along with the relaying of static disassembly/recycling instructions; some materials may also have embedded RFID tags detailing origin, composition, and recycling instructions. The disassembly process and recycling activities may be relayed back to the manufacturer and imported into new modular section designs and updated BIM models. At the manufacturing stage, the BIM model will provide an overall design for the building and the specification of the modular sections. The sensor pack will be able to interact with the BIM model for technical guidance at the manufacturing and on-site assembly stages (fine placement of fittings and modular sections, respectively). It is currently the case that modular units once manufactured and delivered to site are difficult to modify and such changes on site may be made in an ad hoc way often with time delayed communication with the manufacturer. If communication with the manufacturer is made, it is not clear how any learning from such incidents is recorded and fed back into the design (if problems are detected). Using a live-connected IoT approach, both the architect and manufacturer are kept informed of the construction progress and problems are highlighted in a more time efficient manner (this could be facilitated in the future through a live connected view of BIM).

The data flows within the proposed framework for sustainable distributed construction are shown in Figure 4. As can be seen in Figure 4, incoming raw materials for the modular wall manufacturer come with sustainability certification and details of their origin and environmental impact in $\mathrm{CO}_{2}$. The BIM design for the completed modular building is shared with the manufacturer by the architect (incoming and two-way information share). The part manufactured wall modules receive their sensor pack and assist with their fine assembly and placement of fittings, such as doors, windows, and electric sockets, and switches based on the BIM specification; some materials may also have embedded RFID tags detailing origin, composition, and recycling instructions. The completed wall modules are then transported to a local/regional sites for assembly into completed homes. On-site assembly involves information flow between wall sections and workers (and their machinery). In use, the buildings will relay data back to the manufacturer (such as energy performance of house, maintenance/health of wall section data), who may in turn update the wall section design and feed this into updated BIM models. At the disassembly stage, the walls sensor pack may be able to assist in the disassembly process (similar to fine maneuvering of the section as with on-site assembly usage) along with the relaying of static disassembly/recycling instructions emanating from the RFID tags embedded within wall section components. Disassembly process and recycling activities may be relayed back to the manufacturer and imported into new wall section designs and updated BIM models. 


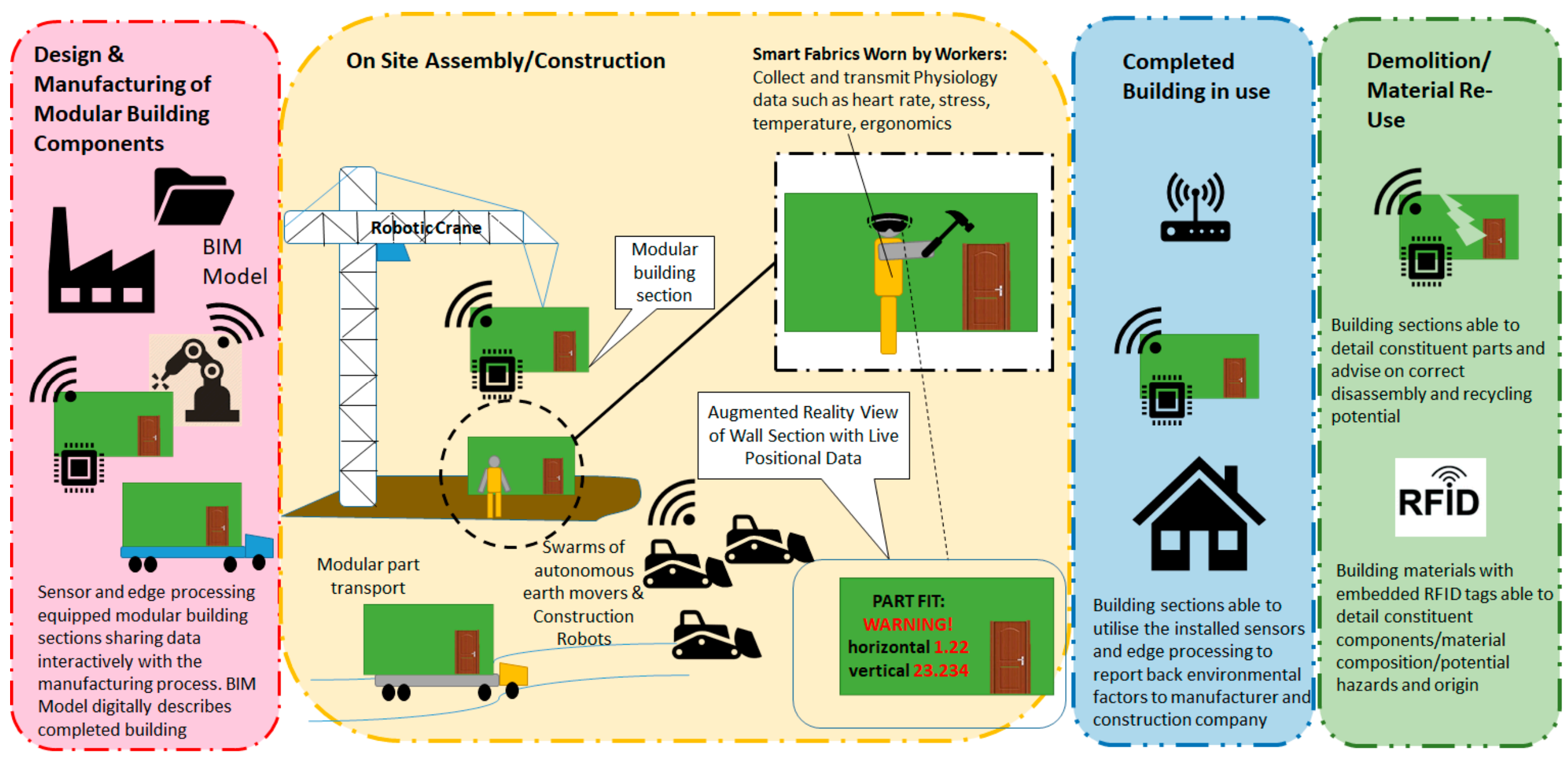

Figure 3. A four-phase model of intelligent assets use in construction (adapted from the work in [50]). 


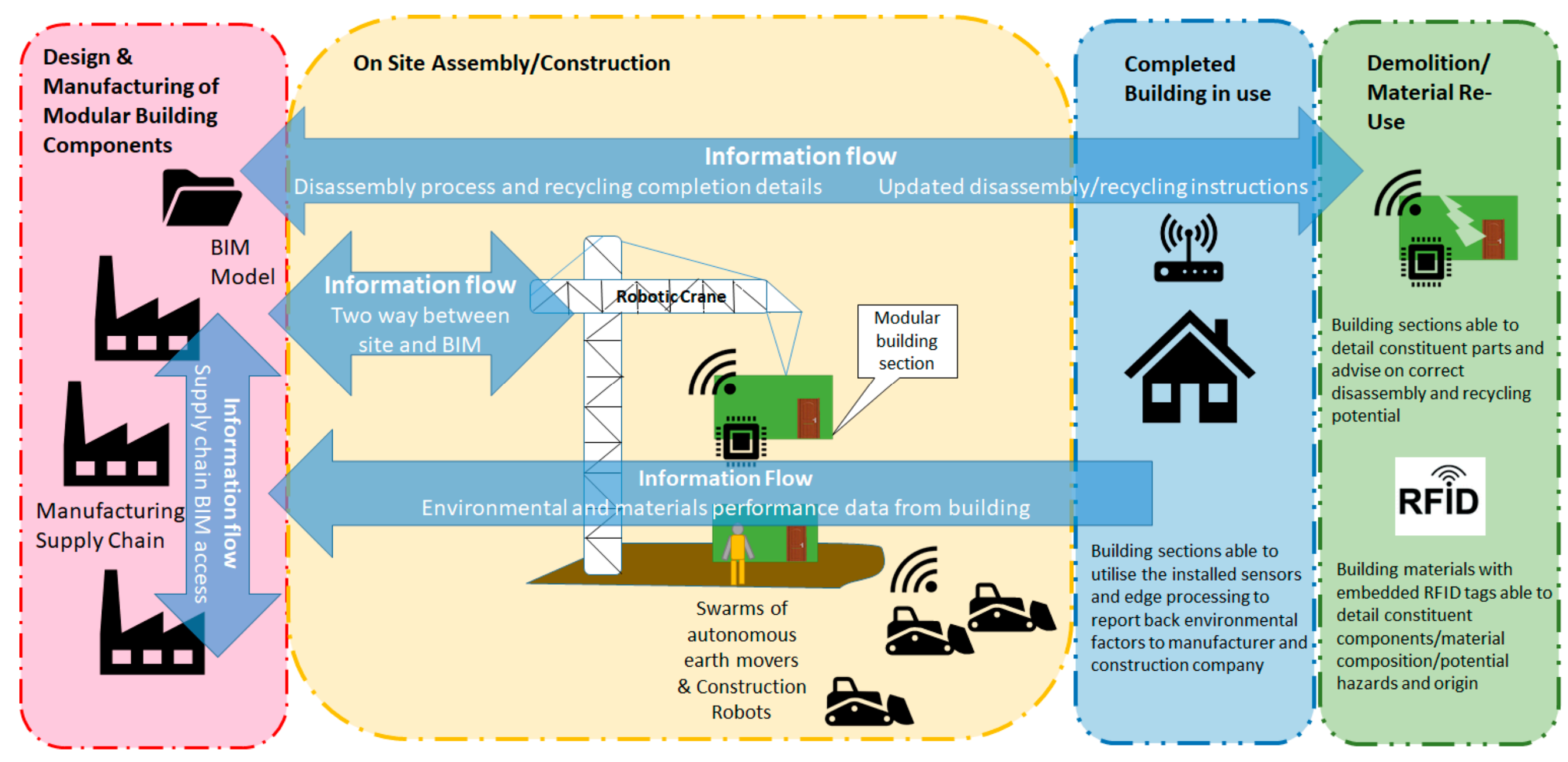

Figure 4. The framework for sustainable distributed construction showing active information flows. 


\section{Concrete as a Modular Sensing Structure}

Concrete is one of the most challenging construction materials to adequately sensorize. It is also the case that concrete is one of the most resource-intensive materials used in construction, and used, in some form, in the majority of construction projects. It makes use of large quantities of aggregate, cement, and water, not to mention its energy-intensive manufacturing processes. As a result, getting a concrete artifact right the first time is important in ensuring sustainable practices. It is used because of its strength and durability and modern offsite manufacturing techniques now make it possible to manufacture modules, such as pillars, offsite before assembling onsite. As seen in Section 5 , sensorizing modules in construction could provide a stream of data to inform various remanufacturing strategies during life and at end of life. For example, most high-rise structures (e.g., skyscrapers) in the urban environment are composed of concrete sections (either poured onsite or manufactured offsite and delivered as pre-built modules). Monitoring the health and performance of this material in structures is very important because a failure in it could lead to disastrous consequences. The use of sensors to perform continuous real-time structural health and performance of these structures from offsite manufacture to construction and then in use could inform process parameters during manufacture as well as load out strategies during use. This will ensure that such structures stay in use longer leading to lower emissions over the building's entire lifecycle.

In literature, most of the structural health monitoring on concrete have focused on attaching sensors to existing structures [56]. In high structures, for example, the measured parameters have mostly included acceleration data caused by wind [57]. This is because acceleration affects modal parameters such as the natural frequency, damping ratio, and mode shape of the structures. It also has a bearing on the internal stresses and strains that could occur in concrete. Obtaining an indication of internal stresses and strains is important because strains in concrete and internal stresses are often the origin of structural failure. As a result, detecting these defects in time could enable longevity of concrete structures [58].

Furthermore, during use, concrete's longevity is also affected by environment (e.g., temperature and humidity), loading, effects of aggressive actions, corrosion of the metal matrix, frost, overload abrasion/erosion, and chemical actions cause by pollution for example [59]. During manufacture of a concrete structure, temperature, and humidity determines the level and speed of concrete curing and drying which then affects the rate or time that a building can be completed.

It is possible that sensors can be embedded during manufacture in order to obtain data about the rate of the concrete curing process and subsequently, the effect it will have upstream in the construction process. The same sensors could then be used during the in-use life of the concrete to monitor the penetration of liquids, contaminates, and changing chemical composition of the structure. This is because the level of humidity could have a bearing on the corrosion taking place on the metal matrix of the concrete structure. This is especially true for structures that have a boundary with water such as tunnels, sewers, bridges, etc. In these structures, the surface integrity of the concrete also has a bearing on the structural integrity of the concrete structure.

$\mathrm{pH}$ levels below $\mathrm{pH} 7$ increase the corrosion rates of these structures. Waste systems, erosion of concrete below the water line due to changes in $\mathrm{pH}$ levels, excessive velocities, and abrasive materials are currently not very well understood. As a result, the introduction of sensors in these areas unconducive for prolonged human stay would be useful [60]. Furthermore, concrete is a composite made up of both a reinforcement which is mostly metal and a matrix which is often a combination of cement and aggregate. From this perspective, it is a heterogeneous material. The constituents and composition of the composite (e.g., type of aggregate used) determines its final surface finish, its performance profile, as well as its durability over its life time. Due to this heterogeneity, the distribution of the effects of environmental factors (such as erosion, temperature, etc.), and in use factors such as loading, would be uneven. Currently, the effect of these various heterogeneous factors on the final product cannot be adequately predicted with the current methodologies [61]. 
This further supports the need to have sensors embedded intelligently in the concrete structure during manufacture in order to derive data for gaining insights into the interplay of these processes.

However, placing the sensors in the concrete needs to be done intelligently because it could affect its structural integrity. Sensors such as electrodes and optical fibers have been proposed [61]. In [61], optical fibers were used as a distributed strain sensor to measure strains in a concrete structure. However, these sensors cannot measure damage directly. Additional strategies are needed. This is partly because the sensor would need to be close to the damage in order to be effective. As a result, the authors of [62] discussed how machine learning techniques could be applied to data collected from sensors located all over the structure.

Nevertheless, sensors embedded in structures would need to be robust to the loading on the structure as well as cope with the high internal temperatures. This raises additional design issues during the conception of the concrete structure. One way of dealing with this is to apply sophisticated machine learning techniques to derive the interplay, and thus optimal configuration, between the materials used in the concrete, manufacturing parameters, matrix, reinforcement structure, and planned usage to know where to optimally place sensors. As embedding sensors could potentially weaken the structure, using computational mechanisms to find where to optimally place sensors while ensuring structural integrity and operational data collection is very important.

One solution to these challenges is through the use of the reinforcement in the concrete structure. The reinforcement could be used as electrodes to probe the concrete structure over its lifetime. This could be effectively converted into a large-scale sensor to monitor the concrete structure. However, signal to noise would deteriorate over long distances and much thought and research would be needed to use them intelligently. Wires could be used to transfer data to the outside where it is connected to an antenna for wireless transmission to a base station using any one of the techniques in Table 2. The wires could be attached to the reinforcement as part of the structure so that structural integrity is not weakened. In some cases, the wire could also serve a dual purpose as a reinforcement as well as signal transmission system/network.

In cases where other sensors are embedded in the concrete, the reinforcement could also transmit power to the sensor boards located in the concrete. Furthermore, research into materials with intrinsic sensing properties, such as carbon nanofibers (CNF), carbon nanotube (CNT), semi-conductive, or conductive nanoparticles, and the possibility of mixing them into concrete to form concrete-based piezoelectric composites is currently undergoing. However, these novel concepts are still plagued by poor sensing repeatability under complex stress conditions. Furthermore, as mentioned previously, research is still needed in order to understand, and thus optimize, the interplay between aggregates and the dispersant methods used [56]. As a final structure will be made up of a number of concrete modules possibly manufactured at different sites, this will result in a sensor network which opens up interesting research challenges. For example, such a network could be configured so that it is powered asynchronously, as and when needed. If there is more use of a particular area compared to others, this section of the structure could be powered more.

The application of data fusion and machine learning techniques could also be applied in deriving insights about structural performance during use as well as inform remanufacturing decisions on the structure. Furthermore, key structural performance (KSP) parameters can be tracked during the useful life of the structure using different types of sensors. Nevertheless, a holistic sensor system and standard data format approach would be needed among manufacturers in order for intelligent software developers to derive maximum impact from the data generated. Moreover, the issues of plug and play in terms of powering these sensor networks raise important challenges that need to be overcome. 


\section{Conclusions}

This paper has presented a framework for sustainable distributed construction, bringing together the concept of Intelligent Assets use in Construction and the Distributed Manufacturing methodology to provide a new framework to permit digitally assisted sustainable modular construction of homes. In providing a four-stage framework for Sustainable Distributed Construction and describing the information flows achievable between these stages, a new agenda has been provided for the whole lifecycle (considering building as an example of the distributed manufacturing paradigm).

The realization of modular construction as a more environmentally acceptable mode of building is at one level limited by current coordination and communication methods used to link building sites and the manufacturing facilities responsible for the modular units. The use of IoT sensing with BIM models to describe a sustainable whole life representation of an individual building draws much from the concept of Digital Twin in that it provides a dynamic living model on which future construction methods may be evaluated. In the construction sector, even though there is a lot of promise, the integration of IoT sensing with BIM is a research topic that is still in its infancy [58]. Nevertheless, the framework presented in this paper proposes and describes the data flows that may potentially be facilitated for a BIM representation to describe a building project as a sustainable asset within the circular economy. At present, BIM models lack significant interoperability and integration with sustainability tools [63]. However, in the future the holistic analysis and integration of captured data from buildings in construction, in use and at the point of demolition is expected to form an important component of future BIM-hosted construction designs. In a similar way to the incorporation of existing data from intelligent assets into future designs via feedback loops [54], the information collected from the different stages of a building's lifecycle will enhance the next generation of construction materials, processes and technology. BIM models provide a valuable template for digital twin implementations for the construction industry, providing a reason for a model's existence throughout the lifecycle of the building they replicate and beyond. Tang et al. [64] provide a research agenda for the connection of IoT devices to BIM models, concluding that the creation of a new set of web services to transport and expose buildings data is a required target. Further efforts will need to be made in the incorporation of Life Cycle Assessment at the design stage directly within BIM models [65-70].

The framework presented in this paper is conceptual and has highlighted the potential issues and variables that could be uncovered when IoT methodology is applied to BIM. The framework was developed as a result of an extensive review into related literature for construction. As with most conceptual works, the proposed framework would need to be validated. In order to validate it, it would need to be applied to a real construction project; this is the next stage for this research.

This paper has also described the use of concrete as a modular sensing structure, proposing that health monitoring of the material in situ along with the recoding of environmental factors over time could help to extend the longevity of such structures. Sensor network and information processing techniques such as that proposed by [71,72] could be applied to monitoring built structures as well as during manufacture to partly mitigating some of the initial pollution costs inherent in the manufacture of this material. The possibility of transforming building components into plug and play IoT-compliant assets provides new scope for whole lifecycle management of concrete use in an industry under pressure to reduce $\mathrm{CO}_{2}$ emissions.

Author Contributions: Conceptualization, C.T and J.O.; Writing, original draft preparation, C.T., J.O., and L.K.S.; Writing, review and editing, C.T., J.O., and L.K.S. All authors have read and agreed to the published version of the manuscript.

Funding: This research received no external funding.

Conflicts of Interest: The authors declare no conflict of interest. 


\section{References}

1. Ogunbiyi, O.; Goulding, J.S.; Oladapo, A.A. An empirical study of the impact of lean construction techniques on sustainable construction in the UK. Constr. Innov. 2014, 14, 88-107. [CrossRef]

2. Innella, F.; Arashpour, M.; Bai, Y. Lean Methodologies and Techniques for Modular Construction: Chronological and Critical Review. J. Constr. Eng. Manag. 2019, 145, 04019076. [CrossRef]

3. Musa, M.F.; Yusof, M.R.; Mohammad, M.F.; Mahbub, R.; Alam, S.; Com, F. Characteristics of Modular Construction: Meeting the Needs of Sustainability and Innovation. In Colloquium on Humanities, Science and Engineering; IEEE: Penang, Malaysia, 2013.

4. Srai, J.S.; Harrington, T.S.; Tiwari, M.K. Characteristics of Redistributed Manufacturing Systems: A comparative study of emerging industry supply networks. Int. J. Prod. Res. 2016, 54, 6936-6955. [CrossRef]

5. Sonego, M.; Echeveste, M.E.S.; Debarba, H.G. The role of modularity in sustainable design: A systematic review. J. Clean. Prod. 2018, 176, 196-209. [CrossRef]

6. Ferdous, W.; Bai, Y.; Ngo, T.D.; Manalo, A.; Mendis, P. New advancements, challenges and opportunities of multi-storey modular buildings-A state-of-the-art review. Eng. Struct. 2019, 183, 883-893. [CrossRef]

7. Goulding, J.; Pour Rahimian, F.; Arif, M.; Sharp, M. New offsite production and business models in construction: Priorities for the future research agenda. Arch. Eng. Des. Manag. 2015, 11, 163-184. [CrossRef]

8. Molavi, J.; Barral, D.L. A Construction Procurement Method to Achieve Sustainability in Modular Construction. Procedia Eng. 2016, 145, 1362-1369. [CrossRef]

9. Hyun, H.; Kim, H.; Lee, H.-S.; Park, M.; Lee, J.-H. Integrated Design Process for Modular Construction Projects to Reduce Rework. Sustainability 2020, 12, 530. [CrossRef]

10. Xu, Z.; Zayed, T.; Niu, Y. Comparative analysis of modular construction practices in mainland China, Hong Kong and Singapore. J. Clean. Prod. 2020, 245, 118861. [CrossRef]

11. Lehmann, S. Low carbon construction systems using prefabricated engineered solid wood panels for urban infill to significantly reduce greenhouse gas emissions. Sustain. Cities Soc. 2013, 6, 57-67. [CrossRef]

12. Boafo, F.E.; Kim, J.-H.; Kim, J.-T. Performance of Modular Prefabricated Architecture: Case Study-Based Review and Future Pathways. Sustainability 2016, 8, 558. [CrossRef]

13. Bonamente, E.; Merico, M.; Rinaldi, S.; Pignatta, G.; Pisello, A.; Cotana, F.; Nicolini, A. Environmental Impact of Industrial Prefabricated Buildings: Carbon and Energy Footprint Analysis Based on an LCA Approach. Energy Procedia 2014, 61, 2841-2844. [CrossRef]

14. Mao, C.; Shen, Q.; Shen, L.; Tang, L. Comparative study of greenhouse gas emissions between off-site prefabrication and conventional construction methods: Two case studies of residential projects. Energy Build. 2013, 66, 165-176. [CrossRef]

15. Kamali, M.; Hewage, K. Life cycle performance of modular buildings: A critical review. Renew. Sustain. Energy Rev. 2016, 62, 1171-1183. [CrossRef]

16. Lehmann, S. Optimizing Urban Material Flows and Waste Streams in Urban Development through Principles of Zero Waste and Sustainable Consumption. Sustainability 2011, 3, 155-183. [CrossRef]

17. Wu, H.; Zuo, J.; Zillante, G.; Wang, J.; Yuan, H. Status quo and future directions of construction and demolition waste research: A critical review. J. Clean. Prod. 2019, 240, 118163. [CrossRef]

18. Leder, N.; Kumar, M.; Rodrigues, V.S. Influential factors for value creation within the Circular Economy: Framework for Waste Valorisation. Resour. Conserv. Recycl. 2020, 158, 104804. [CrossRef]

19. Pan, W.; Gibb, A.G.; Dainty, A.R. Leading UK housebuilders' utilization of offsite construction methods. Build. Res. Inf. 2008, 36, 56-67. [CrossRef]

20. Wuni, I.Y.; Shen, G.Q. Holistic Review and Conceptual Framework for the Drivers of Offsite Construction: A Total Interpretive Structural Modelling Approach. Buildings 2019, 9, 117. [CrossRef]

21. Abbasnejad, B.; Moud, H.I. BIM and Basic Challenges Associated with its Definitions, Interpretations and Expectations. Int. J. Eng. Res. Appl. 2013, 3, 287-294.

22. Alwan, Z.; Jones, P.D.; Holgate, P. Strategic sustainable development in the UK construction industry, through the framework for strategic sustainable development, using Building Information Modelling. J. Clean. Prod. 2017, 140, 349-358. [CrossRef]

23. Robèrt, K.-H.; Schmidt-Bleek, B.; De Larderel, J.A.; Basile, G.; Jansen, J.; Kuehr, R.; Thomas, P.P.; Suzuki, M.; Hawken, P.; Wackernagel, M. Strategic sustainable development - selection, design and synergies of applied tools. J. Clean. Prod. 2002, 10, 197-214. [CrossRef]

24. Gbadamosi, A.-Q.; Mahamadu, A.-M.; Oyedele, L.O.; Akinade, O.O.; Manu, P.; Mahdjoubi, L.; Aigbavboa, C. Offsite construction: Developing a BIM-Based optimizer for assembly. J. Clean. Prod. 2019, 215, 1180-1190. [CrossRef]

25. Adams, K.T.; Osmani, M.; Thorpe, T.; Thornback, J. Circular economy in construction: Current awareness, challenges and enablers. Proc. Inst. Civ. Eng.-Waste Resour. Manag. 2017, 170, 15-24. [CrossRef]

26. Ginga, C.P.; Ongpeng, J.M.C.; Daly, M.K.M. Circular Economy on Construction and Demolition Waste: A Literature Review on Material Recovery and Production. Materials 2020, 13, 2970. [CrossRef]

27. Eberhardt, L.C.M.; Birkved, M.; Birgisdottir, H. Building design and construction strategies for a circular economy. Arch. Eng. Des. Manag. 2020, 1-21. [CrossRef] 
28. MacArthur, E. Towards a Circular Economy: Business Rationale for an Accelerated Transition, The Ellen MacArthur Foundation. 2015. Available online: https://www.ellenmacarthurfoundation.org/assets/downloads/publications/TCE_Ellen-MacArthurFoundation_26-Nov-2015.pdf (accessed on 30 January 2021).

29. Osobajo, O.A.; Oke, A.; Omotayo, T.; Obi, L.I. A systematic review of circular economy research in the construction industry. Smart Sustain. Built Environ. 2020. [CrossRef]

30. Jones, P.; Comfort, D. The construction industry and the circular economy. Int. J. Manag. Cases 2018, 20, 4-15.

31. Stephan, A.; Athanassiadis, A. Towards a more circular construction sector: Estimating and spatialising current and future non-structural material replacement flows to maintain urban building stocks. Resour. Conserv. Recycl. 2018, 129, $248-262$. [CrossRef]

32. Nasir, M.H.A.; Genovese, A.; Acquaye, A.A.; Koh, S.; Yamoah, F. Comparing linear and circular supply chains: A case study from the construction industry. Int. J. Prod. Econ. 2017, 183, 443-457. [CrossRef]

33. Rios, F.C.; Grau, D.; Chong, W.K. Reusing exterior wall framing systems: A cradle-to-cradle comparative life cycle assessment. Waste Manag. 2019, 94, 120-135. [CrossRef] [PubMed]

34. Tingley, D.D.; Cooper, S.; Cullen, J. Understanding and overcoming the barriers to structural steel reuse, a UK perspective. J. Clean. Prod. 2017, 148, 642-652. [CrossRef]

35. Ruiz, L.A.L.; Ramón, X.R.; Domingo, S.G. The circular economy in the construction and demolition waste sector-A review and an integrative model approach. J. Clean. Prod. 2020, 248, 119238. [CrossRef]

36. Ghisellini, P.; Ji, X.; Liu, G.; Ulgiati, S. Evaluating the transition towards cleaner production in the construction and demolition sector of China: A review. J. Clean. Prod. 2018, 195, 418-434. [CrossRef]

37. Ghisellini, P.; Ripa, M.; Ulgiati, S. Exploring environmental and economic costs and benefits of a circular economy approach to the construction and demolition sector. A literature review. J. Clean. Prod. 2018, 178, 618-643. [CrossRef]

38. Tingley, D.D.; Davison, J. Developing an LCA methodology to account for the environmental benefits of design for deconstruction. Build. Environ. 2012, 57, 387-395. [CrossRef]

39. Akinade, O.O.; Oyedele, L.O.; Ajayi, S.O.; Bilal, M.; Alaka, H.A.; Owolabi, H.A.; Bello, S.A.; Jaiyeoba, B.E.; Kadiri, K.O. Design for Deconstruction (DfD): Critical success factors for diverting end-of-life waste from landfills. Waste Manag. 2017, 60, 3-13. [CrossRef]

40. Akanbi, L.A.; Oyedele, L.O.; Omoteso, K.; Bilal, M.; Akinade, O.O.; Ajayi, A.O.; Delgado, J.M.D.; Owolabi, H.A. Disassembly and deconstruction analytics system (D-DAS) for construction in a circular economy. J. Clean. Prod. 2019, 223, 386-396. [CrossRef]

41. Nußholz, J.; Rasmussen, F.N.; Milios, L. Circular building materials: Carbon saving potential and the role of business model innovation and public policy. Resour. Conserv. Recycl. 2019, 141, 308-316. [CrossRef]

42. Pan, X.; Xie, Q.; Feng, Y. Designing recycling networks for construction and demolition waste based on reserve logistics research field. J. Clean. Prod. 2020, 260, 120841. [CrossRef]

43. Buyle, M.; Galle, W.; Debacker, W.; Audenaert, A. Sustainability assessment of circular building alternatives: Consequential LCA and LCC for internal wall assemblies as a case study in a Belgian context. J. Clean. Prod. 2019, 218, 141-156. [CrossRef]

44. Prins, M.; Mohammadi, S.; Slob, N. Radical circular economy. In Proceedings of the CIB Joint International Symposium-Going North for Sustainability: Leveraging Knowledge and Innovation for Sustainable Construction and Development, London, UK, 23-25 November 2015; IBEA Publications Ltd.: London, UK, 2015.

45. Schut, E.; Crielaard, M.; Mesman, M. Circular economy in the Dutch construction sector: A perspective for the market and government. Natl. Inst. Public Heal. Environ. 2015, pp. 1-58. Available online: https://www.rivm.nl/bibliotheek/rapporten/2016 -0024.pdf (accessed on 29 January 2021).

46. Ghaffar, S.H.; Burman, M.; Braimah, N. Pathways to circular construction: An integrated management of construction and demolition waste for resource recovery. J. Clean. Prod. 2020, 244. [CrossRef]

47. Benachio, G.L.F.; Freitas, M.D.C.D.; Tavares, S.F. Circular economy in the construction industry: A systematic literature review. J. Clean. Prod. 2020, 260, 121046. [CrossRef]

48. Munaro, M.R.; Tavares, S.F.; Bragança, L. Towards circular and more sustainable buildings: A systematic literature review on the circular economy in the built environment. J. Clean. Prod. 2020, 260, 121134. [CrossRef]

49. Turner, C.J.; Moreno, M.; Mondini, L.; Salonitis, K.; Charnley, F.; Tiwari, A.; Hutabarat, W. Sustainable Production in a Circular Economy: A Business Model for Re-Distributed Manufacturing. Sustainability 2019, 11, 4291. [CrossRef]

50. Turner, C.; Oyekan, J.; Stergioulas, L.; Griffin, D. Utilizing Industry 4.0 on the Construction Site: Challenges and Opportunities. IEEE Trans. Ind. Inform. 2021, 17, 746-756. [CrossRef]

51. Honic, M.; Kovacic, I.; Rechberger, H. Improving the recycling potential of buildings through Material Passports (MP): An Austrian case study. J. Clean. Prod. 2019, 217, 787-797. [CrossRef]

52. Merrild, H.; Jensen, K.G.; Sommer, J. Building a Circular Future; GXN: Copenhagen, Denmark, 2016.

53. Heisel, F.; Rau-Oberhuber, S. Calculation and evaluation of circularity indicators for the built environment using the case studies of UMAR and Madaster. J. Clean. Prod. 2020, 243, 118482. [CrossRef]

54. Ellen Macarthur Foundation. Intelligent Assets I Ellen Macarthur Foundation 1. 2016. Available online: http://www. ellenmacarthurfoundation.org/publications/intelligent-assets (accessed on 29 January 2021).

55. Ellen MacArthur Foundation. Artificial Intelligence and the Circular Economy-AI as a Tool to Accelerate the Transition. 2019. Available online: http:/ / www.ellenmacarthurfoundation.org/publications (accessed on 29 January 2021). 
56. Taheri, S. A review on five key sensors for monitoring of concrete structures. Constr. Build. Mater. 2019, 204, 492-509. [CrossRef]

57. Zhang, F.; Xiong, H.B.; Shi, W.X.; Ou, X. Structural health monitoring of Shanghai Tower during different stages using a Bayesian approach. Struct. Control. Heal. Monit. 2016, 23, 1366-1384. [CrossRef]

58. Bao, X.; Chen, L. Recent Progress in Distributed Fiber Optic Sensors. Sensors 2012, 12, 8601-8639. [CrossRef] [PubMed]

59. Hobbs, D. Concrete deterioration: Causes, diagnosis, and minimising risk. Int. Mater. Rev. 2001, 46, 117-144. [CrossRef]

60. Taheri, S.; Ams, M.; Bustamante, H.; Vorreiter, L.; Bevitt, J.J.; Withford, M.; Clark, S.M. Characterizing concrete corrosion below sewer tidal levels at chemically dosed locations. Water Res. 2020, 185, 116245. [CrossRef] [PubMed]

61. Sun, X.; Du, Y.; Liao, W.; Ma, H.; Huang, J. Measuring the heterogeneity of cement paste by truly distributed optical fiber sensors. Constr. Build. Mater. 2019, 225, 765-771. [CrossRef]

62. Güemes, A.; Fernandez, A.; Díaz-Maroto, P.F.; Lozano, A.; Sierra-Pérez, J. Structural Health Monitoring in Composite Structures by Fiber-Optic Sensors. Sensors 2018, 18, 1094. [CrossRef] [PubMed]

63. Santos, R.; Costa, A.A.; Silvestre, J.D.; Pyl, L. Informetric analysis and review of literature on the role of BIM in sustainable construction. Autom. Constr. 2019, 103, 221-234. [CrossRef]

64. Tang, S.; Shelden, D.R.; Eastman, C.M.; Pishdad-Bozorgi, P.; Gao, X. A review of building information modeling (BIM) and the internet of things (IoT) devices integration: Present status and future trends. Autom. Constr. 2019, 101, 127-139. [CrossRef]

65. Rezaei, F.; Bulle, C.; Lesage, P. Integrating building information modeling and life cycle assessment in the early and detailed building design stages. Build. Environ. 2019, 153, 158-167. [CrossRef]

66. Santos, R.; Costa, A.A.; Silvestre, J.D.; Pyl, L. Integration of LCA and LCC analysis within a BIM-based environment. Autom. Constr. 2019, 103, 127-149. [CrossRef]

67. Seyis, S. Mixed method review for integrating building information modeling and life-cycle assessments. Build. Environ. 2020, 173, 106703. [CrossRef]

68. Nwodo, M.N.; Anumba, C.J. A review of life cycle assessment of buildings using a systematic approach. Build. Environ. 2019, 162, 106290. [CrossRef]

69. Muller, M.F.; Esmanioto, F.; Huber, N.; Loures, E.R.; Canciglieri, O. A systematic literature review of interoperability in the green Building Information Modeling lifecycle. J. Clean. Prod. 2019, 223, 397-412. [CrossRef]

70. Zoghi, M.; Kim, S. Dynamic Modeling for Life Cycle Cost Analysis of BIM-Based Construction Waste Management. Sustainability 2020, 12, 2483. [CrossRef]

71. Oyekan, J.; Huosheng, H. Toward bacterial swarm for environmental monitoring. In Proceedings of the 2009 IEEE International Conference on Automation and Logistics, Shenyang, China, 5-7 August 2009; pp. 399-404.

72. Oyekan, J.; Hu, H. Ant robotic swarm for visualizing invisible hazardous substances. Robotics 2013, 2, 1-18. [CrossRef] 